\title{
Comparative assessment of changes in pharyngeal airway space in cases of obstructive sleep apnoea with a customized mandibular repositioning appliance - a clinical study
}

Rezeen Aziz*

Sanju Somaiah

Anmol S Kalha

Goutham Reddy

Sunil Muddaiah

Balakrishna Shetty

Coorg Institute of Dental Sciences, Orthodontics and Dentofacial Orthopedics - Virajpet - Karnataka - India.

\section{*Corresponding author:}

Rezeen Aziz

E-mail: rezeen.kkr32@gmail.com

Received: March 18, 2020;

Accepted: November 11, 2020.

DOI: $10.5935 / 1984-0063.20200072$

\begin{abstract}
Objectives: The present study aims at evaluating the effects of a customized mandibular repositioning appliance on the pharyngeal airway, nocturnal sleep patterns, daytime discomfort and occlusal changes in established cases of adult obstructive sleep apnoea. Material and Methods: Ten consecutive patients with a complaint of snoring and disturbed sleep were included in the study. The primary diagnosis was established by the Epworth sleepiness scale, clinical examination, history and subsequently the diagnosis was substantiated through assessment of the pharyngeal airway space on a lateral cephalogram and polysomnography. A customized mandibular repositioning appliance was used to advance the mandible sequentially every 6 months, using 4 sets of the appliance. Pre and post-treatment evaluations were performed to establish, effects and changes in the outcome of obstructive sleep apnoea. Results: The study revealed significant increase in the mean pharyngeal widths of upper airway and velum dimension with antero-superior repositioning of hyoid bone. Epworth sleepiness scale score improved significantly from baseline with clinically evident change in daytime discomforts. Significant decline in the mean apnoea/hypopnea index, oxygen desaturation index, respiratory disturbance index, heart rate, snoring and a significant increase in mean oxygen saturation of arterial blood was observed. No evident change noticed in occlusion except lower incisor inclination. Conclusion: The customized mandibular repositioning appliances are effective in the management of adult obstructive sleep apnoea with a significant improvement observed in the airway patency and polysomnography parameters with clinically non-significant effects on dental occlusion..
\end{abstract}

Keywords: Sleep Apnea; Obstructive; Snoring; Polysomnography; Sleep Apnea Syndromes. 


\section{INTRODUCTION}

Obstructive sleep apnoea (OSA) is a potentially lifethreatening disorder characterized by total or partial obstruction of the upper airway during sleep, leading to repetitive episodes of respiratory events such as apnoeas and hypopnoeas ${ }^{1}$. The cardinal manifestations of OSA are loud snoring, witnessed breathing pauses during sleep, excessive daytime sleepiness, and deficits in neurocognitive function adversely affecting the quality of life $e^{2,3}$. There has been an increasing awareness over the years that patients suffering from OSA are at risk from a wide range of medical complications as a result of nocturnal hypoxia they experience during sleep ${ }^{1}$.

In men older than 40 years of age, more than $50 \%$ snore occasionally, and about 10 to $15 \%$ snore regularly ${ }^{4}$. Among children and adolescents, the prevalence of primary snoring has been reported at $3.2 \%$ to $12.1 \%$, with an estimated prevalence rate of $0.7 \%$ to $10.3 \%$ for OSA $^{5}$. Decreased mandibular and maxillary length, skeletal retrognathism, high mandibular plane angle and inferiorly positioned hyoid bone are characteristic cephalometric findings in sleep-disordered breathing ${ }^{6}$.

The primary diagnosis comprises comprehensive history supported by the use of questionnaires such as Epworth sleepiness scale (ESS), detailed stomatognathic examination, body mass index $(\mathrm{BMI})$, neck circumference calculation, and overnight $\mathrm{PSG}^{7}$. Lateral cephalograms are used for diagnostic purposes and to monitor the changes in airway in response to mandibular protrusion ${ }^{6}$.

Mandibular repositioning appliance (MRA) therapy is a unique, established approach that provides better sleep quality to patients suffering from snoring and mild-to-moderate OSA with excellent patient compliance ${ }^{8}$. Customized MRAs are designed to provide precision fit to act like a retainer for the purpose of eliminating any unwanted tooth movement ${ }^{9}$. MRAs were believed to exert their effects predominantly in the oropharynx and hypopharynx but some studies have suggested an effect on the retropalatal airway as well ${ }^{10}$. Only very few studies in literature explains about the amount of mandibular advancement with MRAs and possible side effects on occlusion ${ }^{11}$. Therefore, the current study aims at comparing the changes in pharyngeal airway space before and after treatment with a customized MRA, and to evaluate the nocturnal sleep patterns and daytime discomfort in patients with OSA along with the effects of MRA on occlusion.

\section{MATERIAL AND METHODS}

The study protocol was approved by the registered ethics committee of the institution. All patients signed an informed consent form and agreed to participate in the study. The sample size consisted of 10 patients selected from 22 consecutive patients reported to the department of orthodontics suffering from snoring and disturbed sleep out of which 7 were males and 3 were females. These 10 patients were selected based on inclusion criteria and through analysing ESS questionnaire and remaining 12 patients were excluded from the study because of satisfying exclusion criteria. The duration of present study was fixed for a period of 2 years from the date of MRA delivery after registration in clinical trial registry (CTRI/2018/04/012923).

\section{Inclusion criteria}

(1) Age range of 27.3-61.6 years; (2) patients diagnosed with OSA; (3) patients willing for MRA therapy; (4) sufficient number of teeth to retain the MRA.

\section{Exclusion criteria}

(1) Maximum mandibular protrusion of less than $6 \mathrm{~mm}$; (2) medically compromised patients with severe systemic illness; (3) severe cariogenic status; (4) periodontally compromised dentition.

\section{Diagnosis}

The primary diagnosis was established by the Epworth sleepiness scale (ESS), clinical examination and detailed history. The subjects in the study were assessed through subjective questionnaire to rule out any pre-existing systemic illness or under medication. The ESS score (range, 0-24) is usually elevated in sleep apnoea patients, indicating a propensity to fall asleep. An ESS score above 10 was considered abnormal ${ }^{12,13}$. All patients were instructed to fill the scale at the initiation of treatment. Subsequently the diagnosis was substantiated through assessment of the pharyngeal airway space on a lateral cephalogram and polysomnography (PSG). Standardized lateral cephalograms were taken at the first appointment and hard and soft tissue radiographic landmarks were located and tracings were made (Figure 1) (Appendix I and II) ${ }^{7}$. Among the subjects, facial form of 7 individuals were mesofacial and 3 individuals had a dolicofacial profile.

An overnight PSG recording with a complete PSG system (Miniscreen Pro, Lowenstein medical technology, Hamburg, Germany) was performed in a full fledge sleep lab. The Miniscreen Pro is a modern PSG system with up to 48 channels having simple integration of eight external signals and digital interface to prismaLINE therapy devices (Weinmann, Lowenstein medical technology). This level 1 PSG study comprised recordings of the pulse rate, apnoea/hypopnea index (AHI), oxygen desaturation index (ODI), respiratory disturbance index (RDI), arterial blood oxygen saturation $\left(\mathrm{SaO}_{2}\right)$, respiratory movements, intensity and duration of snoring, and body positions. Monitoring $\mathrm{SaO}_{2}$ continuously with an ear probe, from which the minimum value of arterial blood oxygen saturation, expressed in percent $\left(\mathrm{SaO}_{2}\right.$

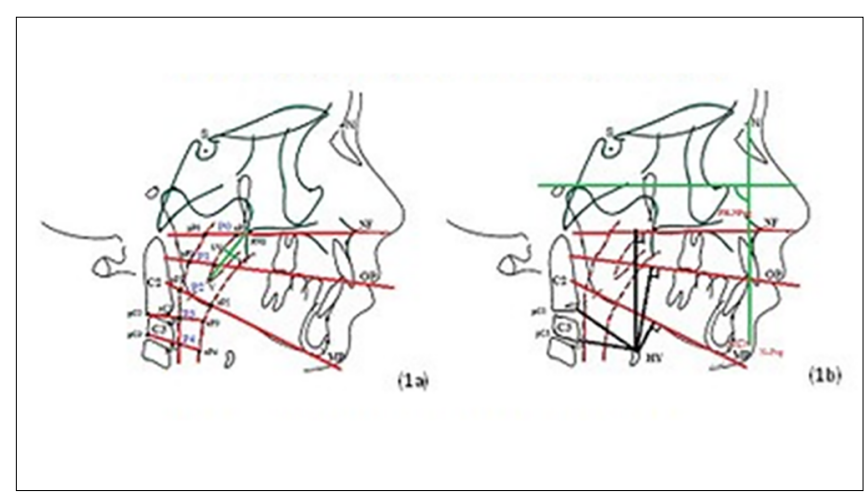

Figure 1. Cephalometric landmarks for reference planes, pharyngeal and velum dimension: A. Hyoid; B. Mandibular position. Definition of landmarks explained in Appendix I and II. 
nadir), was measured. The ODI was calculated and defined as the average number of episodes per hour when the oxygen saturation decreased more than or equal to $5 \%$ from the baseline value followed by determining AHI. According to the American Academy of Sleep Medicine (AASM), AHI is categorized into mild (5-15 events/hour), moderate (15-30 events/hour), and severe $(>30 \text { events } / \text { hour })^{14}$. AHI was originally calculated using previous AASM hypopnea scoring criteria (AHI(Chicago)), requiring either $>50 \%$ airflow reduction or a lesser airflow reduction with associated $>3 \%$ oxygen desaturation or arousal. AHIs using the "recommended" (AHI (Rec)) and the "alternative" (AHI(Alt)) hypopnea definitions of the AASM Manual for Scoring of Sleep and Associated Events were then derived. For AHI(Rec), hypopneas were required to have $>$ or $=30 \%$ airflow reduction and $>$ or $=4 \%$ desaturation; and for AHI(Alt), hypopneas were required to have $>$ or $=50 \%$ airflow reduction and $>$ or $=3 \%$ desaturation or arousal ${ }^{15}$. $\mathrm{RDI}$ expresses the combined values of both $\mathrm{AHI}$ and respiratory effort related arousal (RERA).

\section{PROCEDURE}

A dental impression of the upper and lower arch was made using polyvinyl siloxane (PVS) impression material for the fabrication of MRA. Bite registration was carried out using George Gauge with mandibular advancement of $60 \%$ of maximum mandibular protrusion. Vertical opening of mandible was kept as low as possible around $3 \mathrm{~mm}$ using standardized $3 \mathrm{~mm}$ bite fork, which was custom made by Prosomnus Sleep Tecbnologies, USA, in contrast to routinely available standard $2 \mathrm{~mm}$ and $5 \mathrm{~mm}$ bite fork. Custom made MRA $\left(\mathrm{MicrO}_{2}\right.$ Sleep \& Snore device - Prosomnus ${ }^{T M}$ USA) (Figure 2) was fabricated utilizing CAD/CAM digital technology. The appliance is made of high-grade polymethyl methacrylate (PMMA), which ensures decreased monomer leaching and further polymerization shrinkage. One-piece construction of appliance without moving parts assures precision fit to the teeth nullifying any unwanted tooth movement. Maintaining vertical opening of jaws at $3 \mathrm{~mm}$ minimizes any temporomandibular joint (TMJ) complications. Mandibular advancement was accomplished using 4 sets of the appliance. The first set (namely U0, L0) of appliance was considered baseline in which the mandible is positioned $3 \mathrm{~mm}$ distal to the initial recorded bite. The consecutive sets of appliances have $1 \mathrm{~mm}$ of advancement each and by using the last set of appliance; the mandible will end at a point of $60 \%$ of maximum mandibular protrusion (Figure 3). In every 6 months, upgradation of consecutive set of appliance was carried out and the patients were advised to use MRA every night during sleep for 2 years.

At the end of treatment lateral cephalograms, ESS and PSG were again repeated and the data were statistically evaluated. To determine the efficacy and efficiency of customized MRA, an elaborate examination of the pre and post-treatment dental occlusion was done on prepared study models in terms of overjet, overbite, intercanine and intermolar width in both the arches and interincisal angle, U1 - PP, L1 - MP as a lateral cephalometric parameter.

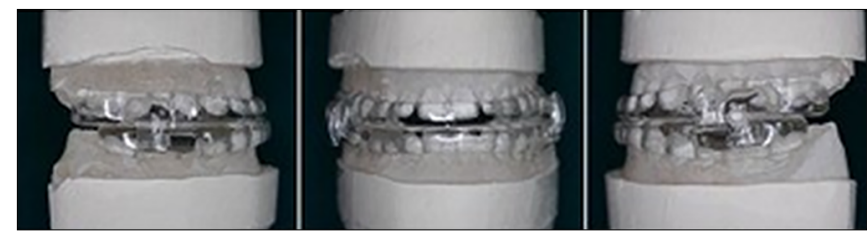

Figure 2. Customized mandibular repositioning appliance (MicrO2 Sleep \& Snore device, ProsomnusTM, USA). Fabricated through CAD/CAM technology ensuring a precision fit.

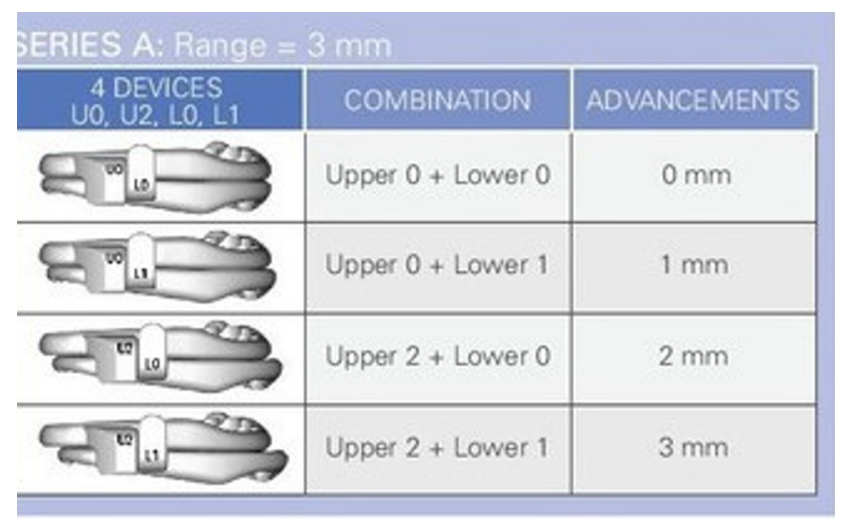

Figure 3. MicrO2 Sleep and snore device for mandibular sequential advancement using 4 set of appliance. Device number highlighted over the vertical post represents the amount of advancement.

\section{Statistical analysis}

Statistical analysis was performed using statistical package (SPSS software, IBM version 23, Armonk, New York, USA). The Kolmogorov-Smirnov test confirmed the sample normality. Cohen's was used to calculate the effect size and it varied from 0.4 to 1.1. It was verified that all the measures were presented within the nullity hypothesis because all the values obtained indicated a value of $p<0.05$ and this also confirmed the use of parametric test. Statistical methods used were descriptive statistics including median, mean and standard deviation and inferential statistics including the students paired t test, which was used to compare pre-treatment and posttreatment cephalometric variables, ESS score, PSG parameters, and variables for detecting changes in occlusion. The level of significance was set at 0.05 at $95 \%$ confidence interval.

\section{RESULTS}

The demographic data of the 10 consecutive patients reported to department of orthodontics with a complaint of snoring and disturbed sleep were analysed. The age of patients ranged from 27.3-61.6 years with a mean of 41.9 years. The subject's height $(\mathrm{cm})$ and weight $(\mathrm{kg})$ were measured with a mean of $167.9 \pm 6.5$ and $77.6 \pm 8.3$, respectively. The BMI was calculated using the method described by Revicki and Israel $(1986)^{16}(\mathrm{BMI}=$ weight $\mathrm{kg} / \mathrm{height}$ $\mathrm{m}^{2}$ ). Most of the subjects were overweight, with a BMI of $28.2 \mathrm{~kg} /$ $\mathrm{m}^{2}$ (range 25.3-32.6) and standard deviation of $2.57 \mathrm{~kg} / \mathrm{m}^{2}$. Posttreatment evaluation of BMI showed non-significant change from pre-treatment values and in the present study no correlation was established between pharyngeal airway width and BMI. The neck circumference ranged from 16-19.5 inches with a mean of $18.25 \pm 1.13$ inches before treatment with clinically non- 
significant change observed after completion of treatment. All 10 patients successfully completed the duration of study with no exclusion of subjects at any point of time.

\section{Duration of appliance wear}

The patients follow up was done every month and to evaluate the frequency of appliance wear the patients were asked to fill a feedback form describing the difficulties faced during appliance wear everyday using a series of 10, YES/NO questions along with record of hours of sleep per day for the respective month. The appliance was worn by the patients for a period of 2 years with a mean duration of 6.4 hours every night with a standard deviation of 0.516 .

\section{Lateral cephalometric results}

Pharyngeal dimensions
There was a significant increase in the mean pharyngeal widths of upper airway at P0, P1, P2, P3, P4 in relation to 5 reference planes $\mathrm{NF}, \mathrm{OP}, \mathrm{MP}, \mathrm{aC} 2 \mathrm{pC} 2, \mathrm{aC} 3-\mathrm{pC} 3$, respectively, after MRA treatment (Table 1).

Mean pharyngeal width P0 at the level of NF before treatment was $18.00 \pm 1.94$ which showed statistically highly significant $(\phi$-value $<0.05)$ change in the mean pharyngeal width of $18.80 \pm 1.81$ following treatment. Accordingly, statistically significant increase was observed in mean pharyngeal width P1 at the level of OP from 9.70 \pm 2.21 to $11.50 \pm 1.58$. A highly significant improvement in pharyngeal width P2 was evident in lateral cephalogram following MRA treatment compared to baseline $(10.60 \pm 2.01$ vs. $12.30 \pm 1.88 ; p=0.00)$. Mean pharyngeal width $\mathrm{P} 3$ at the level of $\mathrm{aC} 2-\mathrm{pC} 2$ and $\mathrm{P} 4$ at the level of $\mathrm{aC} 3-\mathrm{pC} 3$ before treatment was $11.70 \pm 1.94$ and $12.60 \pm 1.64$, respectively, which showed statistically significant improvement in pharyngeal width by $13.40 \pm 1.50$ and $13.70 \pm 2.00$.

Table 1. Comparison of pre-treatment and post-treatment lateral cephalometric variables.

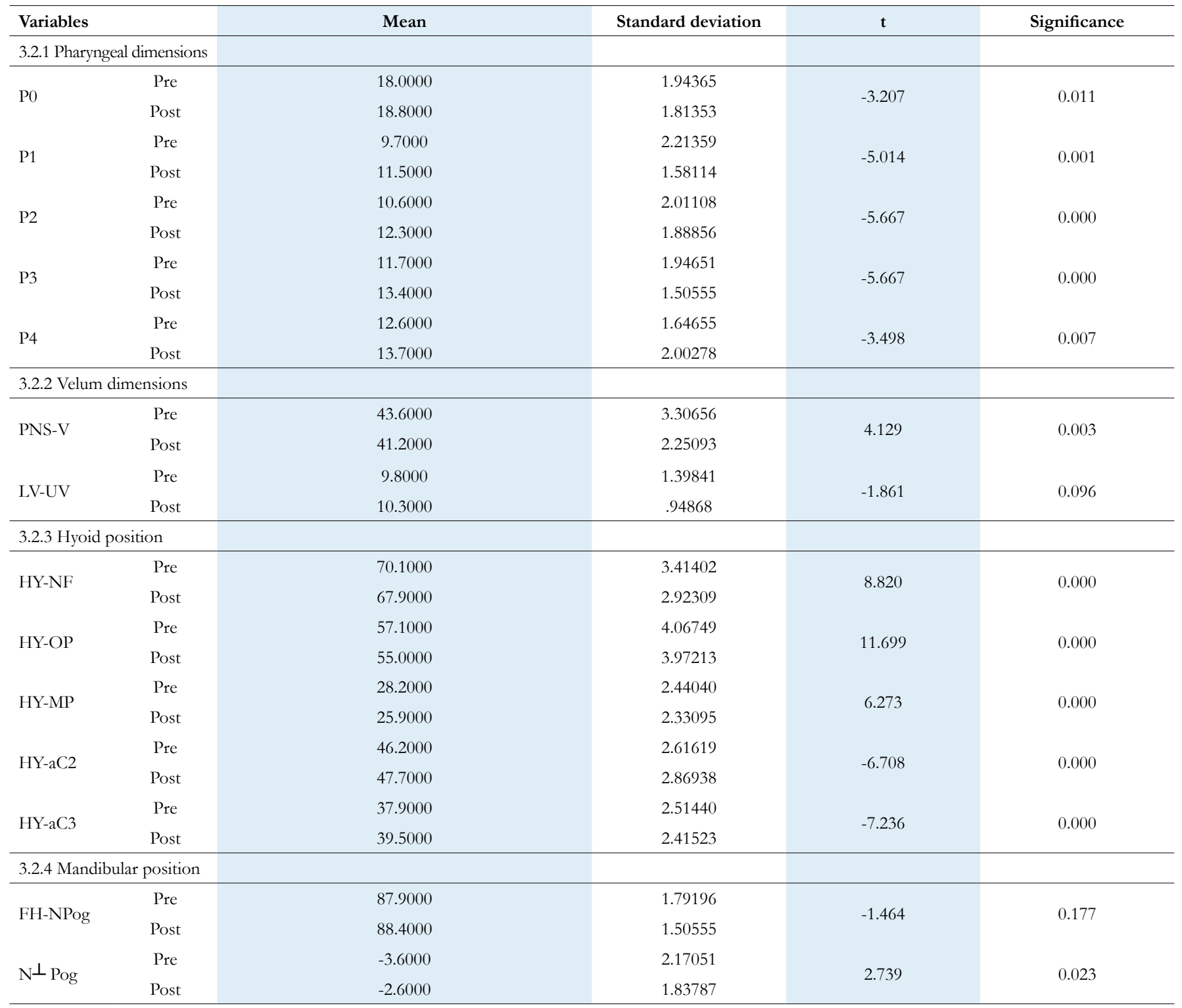


Amount of mandibular advancement was standardized as $60 \%$ of maximum mandibular protrusion in each individual. The average amount of advancement in 10 subjects were within a range of $5-7 \mathrm{~mm}$ with a mean of $6.11 \pm 0.32$ and no evidence obtained to correlate with amplification of airway and amount of advancement since all individuals had similar amount of increase in pharyngeal airway width irrespective of amount of advancement and age of the patient.

\section{VELUM DIMENSIONS}

The present study observed mean velum length PNS-V was significantly reduced following treatment when compared with pre-treatment values ( $43.60 \pm 3.30$ vs. $41.20 \pm 2.25 ; p=0.003$ ). Non-significant increase was noted with the mean velum thickness LV-UV following treatment (Table 1).

\section{Hyoid position}

Highly significant decrease in mean hyoid position

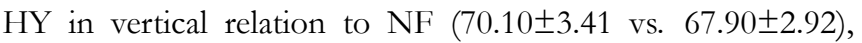

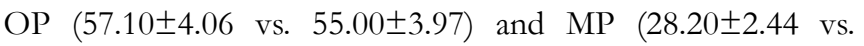
$25.90 \pm 2.33$ ) was evident in post-treatment lateral cephalogram suggestive of superior repositioning of hyoid bone. In sagittal plane, mean hyoid position $\mathrm{HY}-\mathrm{aC} 2$ and $\mathrm{HY}-\mathrm{aC} 3$ showed a statistically significant increase of $(46.20 \pm 2.61$ vs. $47.70 \pm 2.86)$ and (37.90 \pm 2.51 vs. $39.50 \pm 2.41)$, respectively, suggestive of anterior repositioning of hyoid bone (Table 1 ).

\section{Mandibular position}

Non-significant increase in the mean mandibular position FH-NPog from $87.90 \pm 1.79$ to $88.40 \pm 1.50$ with a $\mathrm{p}$ value of 0.177 and a significant increase in the mean mandibular position $\mathrm{N} \perp \mathrm{Pog}$ from $-3.60 \pm 2.17$ to $-2.60 \pm 1.83$ suggestive of anterior repositioning of pogonion after MRA treatment (Table 1). There was no correlation established between rotation of mandibular plane with amount of advancement and facial profile from the results of present study.

\section{Polysomnography results}

Overnight PSG studies revealed a highly significant reduction in the mean AHI, ODI, RDI, HR, snoring values and a significant increase in the mean $\mathrm{SaO}_{2}$ following MRA treatment (Table 2). A significant decrease in mean AHI following MRA treatment was observed $(41.99 \pm 12.14$ vs. $24.71 \pm 7.12)$ with similar findings among other parameters. Mean ODI and RDI values showed significant reduction (53.04 \pm 11.04 vs. $21.24 \pm 5.06)$ and ( $42.48 \pm 12.46$ vs. $24.78 \pm 7.12$ ), respectively. The mean heart rate among the study samples revealed a significant decrease from $68.03 \pm 3.07$ to $55.00 \pm 8.38$. On comparison with baseline findings, mean snoring rate showed a significant reduction from $55.19 \pm 8.38$ to $34.16 \pm 4.66$. A statistically significant improvement was evident in mean $\mathrm{SaO}_{2}$ levels following treatment $(86.78 \pm 3.31$ vs. $96.12 \pm 1.57$; $p=0.00)$ and overall findings were depicted through graphical representation (Figure 4).

\section{Questionnaire based results}

ESS questionnaire was used to evaluate subjective symptoms associated with OSA and to score daytime discomforts. On comparison with post-treatment findings, a statistically significant improvement in mean ESS score was observed following MRA treatment from $16.20 \pm 2.61$ to $5.80 \pm 2.09$ (Table 3).

\section{Effects on dental occlusion}

The mean interincisal angle measured on pre and posttreatment lateral cephalogram exhibited a statistically significant decrease from $128.80 \pm 3.76$ to $126.90 \pm 3.87$ suggestive of proclination of incisors following MRA treatment. Mean U1 - PP and L1 - MP substantiates the above finding through highlighting non-significant decrease in U1 - PP from $111.60 \pm 2.11$ to $111.40 \pm 2.17$ and statistically significant increase in L1 - MP from $94.30 \pm 1.82$ to $95.20 \pm 1.87$ suggestive of proclined lower incisors (Table 4).

Mean intercanine width in the maxillary arch showed a non-significant change from $30.30 \pm 0.91$ to $30.15 \pm 0.74$ with a corresponding non-significant change evident in mandibular intercanine width ( $25.85 \pm 0.88$ vs $25.90 \pm 0.96)$. Accordingly, mean intermolar width in maxillary and mandibular arch displayed a statistically non-significant decrease from $38.300 \pm 1.567$ to $38.25 \pm 1.703$ and $34.150 \pm 1.811$ to $34.050 \pm 1.535$, respectively. Mean overjet measured on pre and post-treatment study models showed statistically non-significant decrease from $3.400 \pm 0.658$ to $3.100 \pm 0.774$. Similarly, with overbite also non-significant change from $2.650 \pm 0.668$ to $2.600 \pm 0.459$ was noted (Table 4).

\section{DISCUSSION}

MRAs has been used as an alternative treatment modality to CPAP for OSA treatment which is designed to improve upper airway dimension through alteration of jaw and tongue position, thereby preventing pharyngeal collapsibility ${ }^{17}$. MRAs were advocated as first-line therapy in patients with mild-to-moderate OSA and in more severe OSA patients who were intolerant to CPAP therapy by AASM ${ }^{18}$. In the current study, a positive effect was established in patients with severe OSA, a result that was supported by research of Cohen $(1998)^{19}$, which reported that 9 out of 15 patients $(60 \%)$ treated using MRA with moderate to severe OSA exhibited a post-treatment RDI of $<5^{19}$.

MRAs can be either custom-made or bought readymade over the counter. Ready-made MRAs offer the potential advantages of being easily available, at relatively low cost. Readymade MRAs unfortunately are limited in their design, by the very fact that the manufacturer is attempting to cater to the needs of a very diverse population, with inherent differences in the size of their jaws and ability to protrude their mandible. In turn, the inherent malleability of these devices potentially compromises their $\mathrm{fit}^{20}$. In contrast to ready-made MRAs, customized devices are designed for a retainer-like fit, for the purpose of mitigating the risk of unwanted tooth movement through use of interdental embrasure adaption, or undercuts, for retention. 
Table 2. Comparison of pre-treatment and post-treatment polysomnography parameters.

\begin{tabular}{|c|c|c|c|c|c|c|}
\hline Variables & & Median & Mean & Standard deviation & $\mathrm{t}$ & Significance \\
\hline \multirow{2}{*}{ AHI $(/ \mathrm{h})$} & Pre & 40.45 & 41.9900 & 12.14985 & \multirow{2}{*}{7.625} & \multirow{2}{*}{0.000} \\
\hline & Post & 23.3 & 24.7100 & 7.12436 & & \\
\hline \multirow{2}{*}{ ODI $(/ \mathrm{h})$} & Pre & 54.10 & 53.0400 & 11.04880 & \multirow{2}{*}{10.287} & \multirow{2}{*}{0.000} \\
\hline & Post & 20.3 & 21.2400 & 5.06671 & & \\
\hline \multirow{2}{*}{$\mathrm{RDI}(/ \mathrm{h})$} & Pre & 40.85 & 42.4800 & 12.46478 & \multirow{2}{*}{7.518} & \multirow{2}{*}{0.000} \\
\hline & Post & 23.6 & 24.7800 & 7.12270 & & \\
\hline \multirow{2}{*}{$\mathrm{SaO} 2(\%)$} & Pre & 86.55 & 86.7800 & 3.31186 & \multirow{2}{*}{-8.116} & \multirow{2}{*}{0.000} \\
\hline & Post & 96.25 & 96.1200 & 1.57959 & & \\
\hline \multirow{2}{*}{ HR (bpm) } & Pre & 68.8 & 68.0300 & 3.07790 & \multirow{2}{*}{13.598} & \multirow{2}{*}{0.000} \\
\hline & Post & 53.95 & 55.0000 & 2.86201 & & \\
\hline \multirow{2}{*}{ SNORING (\%) } & Pre & 55.5 & 55.1900 & 8.38510 & \multirow{2}{*}{8.750} & \multirow{2}{*}{0.000} \\
\hline & Post & 33.95 & 34.1600 & 4.66862 & & \\
\hline
\end{tabular}

AHI: Apnoea/hypopnea index; ODI: Oxygen desaturation index; RDI: Respiratory disturbance index; SaO2: Oxygen saturation of arterial blood; HR: Heart rate.

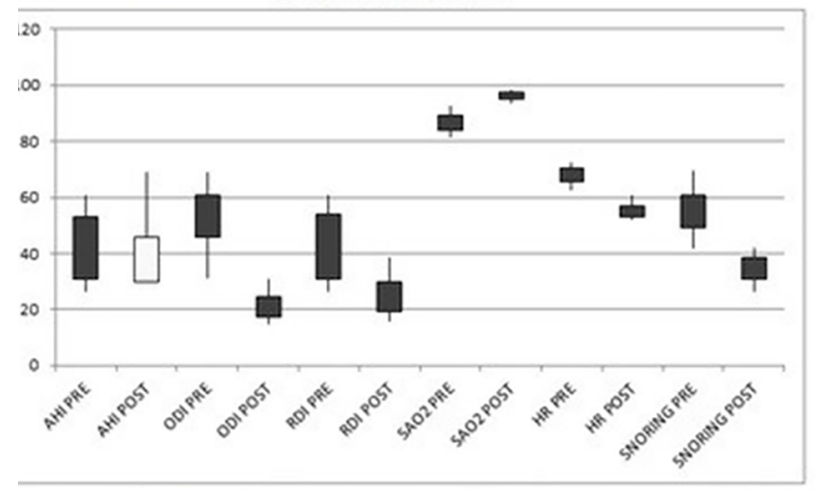

AHI- Apncea/hypopnea index, OOI- Oxygen desaturation index, ROl- Respiratory disturbance index, SaO- Oxygen saturation of arterial blood. HR. Heart rate

Figure 4. Graphical representation of pre-treatment and post-treatment comparison of mean diference in PSG parameters.

Table 3. Comparison of pre-treatment and post-treatment ESS scor

\begin{tabular}{lc|c|c|c|c}
\hline Variables & Mean & $\begin{array}{c}\text { Standard } \\
\text { deviation }\end{array}$ & t & Significance \\
\hline ESS & Pre & 16.2000 & 2.61619 & 9.476 & 0.000 \\
Score & Post & 5.8000 & 2.09762 & & \\
\hline
\end{tabular}

The current study substantiates the efficiency of custom fit MRA with very minimal negative effects in occlusion apart from angular relationships of incisors with their respective jaws. These devices provide a precision fit and sequential advancement through multiple set of appliance, which permit the patient gradually learn to advance the jaw forward, improving their effectiveness. Johal et al. (2017) ${ }^{20}$ compared the effectiveness of a custom-made versus ready-made MRAs in the management of OSA which demonstrated significant clinical effectiveness of a custom-made mandibular repositioning device over ready-made particularly in terms of patient compliance and tolerance. A comparative study by Vanderveken et al. (2013) ${ }^{21}$, concluded that excessive daytime sleepiness persisted in $45 \%$ and $55 \%$ of patients with the custom-made and ready-made MRAs, respectively.

The gold standard in diagnosing OSA is a full-night PSG recording in a laboratory with the primary outcome measure of apnoea-hypopnea index ${ }^{22,23}$. We found a strong positive correlation between PSG parameters of OSA severity and the amount of improvement in those PSG parameters with the device. In the current study, the mean oxygen saturation level improved from $86.78 \% \pm 3.31 \%$ to $96.12 \% \pm 1.57 \%$. Similar improvements in oxygen saturation levels with MRAs were reported by Bernhold and Bondemark (1998) ${ }^{24}$, Bonham et al. $(1998)^{25}$, Gavish et al. (2001) ${ }^{26}$, and Lowe et al. (1986) ${ }^{27}$. Mean AHI before treatment was $41.99 \pm 12.14$, which in turn reduced to $24.71 \pm 7.12$ after MRA treatment. This confirms the observation by Ferguson et al. $(2001)^{28}$, who reported that $62.5 \%$ of their patients exhibited a reduction in the AHI by using an MRA.

Current study results shows mean ODI before treatment was $53.0400 \pm 11.04880$ with a significant post-treatment change of $21.2400 \pm 5.06671$. As per the study conducted by Fransson et al. (2001) 4 , 18 of the 22 OSA patients treated with MRA had a decreased ODI values by $\geq 50 \%$ with a significant change from 15.4 to $3.5(p<0.001)$. Heart rate variability (HRV) reflects the status of the autonomic nervous system (ANS) in patients with physiological and pathological conditions, providing a unique index to identify $\mathrm{OSA}^{29}$. Numerous studies have demonstrated that the recurrence of the progressive-bradycardia/abrupttachycardia pattern observed in patients with OSA is likely the response of ANS to apnoeic events ${ }^{30}$. The mean heart rate among the study samples showed a significant decrease from $68.0300 \pm 3.07790$ to $55.0000 \pm 8.38510$. Gauthier et al. $(2011)^{31}$ found that heart rate significantly decreased at follow-up (mean 40.9 months) compared to baseline after using an MRA. Similar findings were reported by Gotsopoulos et al. (2004) ${ }^{32}$, who assessed the heart rate derived from the 24-hour ambulatory blood pressure monitoring (ABPM).

ESS scores provide a measurement of a patient's general level of daytime sleepiness, from low to very high in a variety of situations ${ }^{33}$. A positive correlation between pre-treatment values of ESS and AHI is helpful to distinguish patients with mild, moderate, and severe OSA according to the ESS scores. Murray $(1991)^{33}$ reported similar findings and in our study, there 
Comparative assessment of changes in the pharyngeal airway

Table 4. Comparison of pre-treatment and post-treatment dental occlusion.

\begin{tabular}{|c|c|c|c|c|c|c|}
\hline \multicolumn{3}{|l|}{ Variables } & Mean & Standard deviation & $\mathrm{t}$ & Significance \\
\hline \multirow{2}{*}{\multicolumn{2}{|c|}{$\begin{array}{l}\text { Inter incisal } \\
\text { angle (o) }\end{array}$}} & Pre & 128.8000 & 3.765 & \multirow{2}{*}{4.6696} & \multirow{2}{*}{0.0000} \\
\hline & & Post & 126.9000 & 3.871 & & \\
\hline \multirow{2}{*}{\multicolumn{2}{|c|}{ U1 - PP (o) }} & Pre & 111.6000 & 2.118 & \multirow{2}{*}{1.0000} & \multirow{2}{*}{0.1717} \\
\hline & & Post & 111.4000 & 2.170 & & \\
\hline \multirow{2}{*}{ L1 - MP (o) } & & Pre & 94.3000 & 1.828 & \multirow{2}{*}{3.8571} & \multirow{2}{*}{0.0019} \\
\hline & & Post & 95.2000 & 1.873 & & \\
\hline \multirow{4}{*}{$\begin{array}{l}\text { Inter canine } \\
\text { width (mm) }\end{array}$} & \multirow{2}{*}{ Max } & Pre & 30.3000 & 0.918 & \multirow{2}{*}{1.4055} & \multirow{2}{*}{0.0967} \\
\hline & & Post & 30.1500 & 0.747 & & \\
\hline & \multirow{2}{*}{ Mand } & Pre & 25.8500 & 0.883 & \multirow{2}{*}{0.0000} & \multirow{2}{*}{0.5000} \\
\hline & & Post & 25.9000 & 0.966 & & \\
\hline \multirow{4}{*}{$\begin{array}{l}\text { Inter canine } \\
\text { width }(\mathrm{mm})\end{array}$} & \multirow{2}{*}{ Max } & Pre & 38.3000 & 1.567 & \multirow{2}{*}{0.3611} & \multirow{2}{*}{0.3611} \\
\hline & & Post & 38.2500 & 1.703 & & \\
\hline & \multirow{2}{*}{ Mand } & Pre & 34.1500 & 1.811 & \multirow{2}{*}{0.4803} & \multirow{2}{*}{0.3212} \\
\hline & & Post & 34.0500 & 1.535 & & \\
\hline \multirow{2}{*}{\multicolumn{2}{|c|}{ Overjet (mm) }} & Pre & 3.4000 & 0.658 & \multirow{2}{*}{1.6269} & \multirow{2}{*}{0.0690} \\
\hline & & Post & 3.1000 & 0.774 & & \\
\hline \multirow{2}{*}{\multicolumn{2}{|c|}{ Overbite (mm) }} & Pre & 2.6500 & 0.668 & \multirow{2}{*}{0.4285} & \multirow{2}{*}{0.3391} \\
\hline & & Post & 2.6000 & 0.459 & & \\
\hline
\end{tabular}

U1 - PP: Upper incisor to palatal plane; L1 - MP: Lower incisor to mandibular plane.

was a highly significant reduction in the mean ESS score from $16.20 \pm 2.61$ to $5.80 \pm 2.09$ after MRA treatment. Improvement in ESS score with the MRA was also reported by Cozza et al. $(2004)^{34}$, Hammond et al. $(2007)^{35}$, Tan et al. $(2002)^{36}$, Giannasi et al. (2013) ${ }^{37}$, and Blanco et al. (2005) ${ }^{38}$. As with any questionnaire-based scale, the ESS is also limited by the subject's ability to read and understand the questionnaire and to answer the questions honestly.

The antero-posterior dimension at the smallest crosssection of the airway shows the severity of the obstruction of the upper airway in the sagittal plane. In the current study posterior airway space, i.e., the space between the base of the tongue and the posterior oropharynx in relation to NF, OP, $\mathrm{MP}$, base of $\mathrm{C} 2$, the base of $\mathrm{C} 3$ was significantly increased from baseline with MRA therapy. Similar results were reported by Schmidt-Nowara et al. (1991) ${ }^{39}$ and another cephalometric study of 10 patients with OSA by Johnson et al. $(1992)^{40}$ showed a $56 \%$ mean increase in posterior airway space when maximal mandibular protrusion was compared to the rest position after MRA treatment. The study sample showed a significant decrease in the mean velum length from $43.6 \pm 3.3$ to $41.2 \pm 2.2$ after MRA treatment. Similar results were reported by Eveloff et al. $(1994)^{41}$ with an associated shortening of the soft palate length following the use of MRA.

The hyoid bone plays an important role in maintaining the upper airway dimension ${ }^{42}$. Because it serves as an anchor for the lingual musculature, it has received considerable attention, and inferior positions of this bone have been widely reported in patients with $\mathrm{OSA}^{43}$. Recent studies have suggested that the inferior position of the hyoid bone might not be a predisposing factor for airway obstruction, but rather a compensatory response ${ }^{44}$. Tourne $(1991)^{45}$ noted that a drop in the hyoid position represents an attempt to secure a relatively constant anterior-posterior dimension of the airway. In the present study, before MRA treatment hyoid bone was found inferiorly and posteriorly placed in vertical relation to NF, OP, MP, and sagittal relation to $\mathrm{aC} 2$ and $\mathrm{aC} 3$, respectively, with a highly significant post-treatment change suggestive of hyoid bone repositioned superiorly and anteriorly. In a study conducted by Fransson et al. (2002) ${ }^{7}$ the average linear distances between the hyoid bone and the 2 reference lines, i.e., nasal line (NL) and mandibular line (ML), had increased significantly. The change in the position of the hyoid bone relative to the position of the mandible could be caused by a change in muscular activity - an adaptation to using the MPD for 6 to 7 hours per night - and not a permanent change in mandibular position, as in surgical mandibular advancement. The mandibular position in relation to the skull base was measured with an angular reading $\mathrm{FH}-\mathrm{NPOg}$ and a linear distance $\mathrm{N} \perp$ Pog which showed a non-significant increase in mean FH-NPog and a significant increase in $\mathrm{N} \perp \mathrm{Pog}$ suggestive of anterior repositioning of the chin. As per the study conducted by Bondemark $(2000)^{46}$, there was a significant change in mandibular position following MRA therapy and the observed change was temporary in nature.

\section{Limitations of the study}

In the present study mode of investigation used to detect pharyngeal airway changes was lateral cephalogram. Cephalometric radiographs are 2-dimensional images and do not necessarily correlate with 3-dimensional measurements and also the imaging is usually performed in an upright posture (which is not a natural sleeping position compared with supine position $)^{7}$. Also, the airway width was measured in the sagittal plane, which was not relevant according to Ryan et al. (1999) ${ }^{10}$ 
and Kyung et al. $(2005)^{47}$, who observed that the oral appliance enlarges the pharynx to a greater degree in the lateral plane than in the sagittal plane at the retro palatal and retroglossal levels of the pharynx. Therefore, future studies could evaluate and compare different airway parameters, such as airway width in transverse plane and airway volume with $\mathrm{CBCT}$ after long-term use of MRA.

\section{CONCLUSION}

The current study confirms that customized MRA is a valid therapeutic option for patients with mild-to-moderate OSA and for severe OSA patients who are non-compliant towards CPAP, if the improvement of respiratory parameters can be confirmed during follow-up PSGs. In this study, the patient's reports of reduced daytime sleepiness, reduced snoring, and improvement in nocturnal sleep pattern, underline the therapeutic efficacy of customized MRA treatment, which is predominantly due to improvements in pharyngeal dimensions and hyoid bone position with minimal side effects in dental occlusion, even though angular relationship of incisors exhibited minor change in lateral cephalogram, which was clinically irrelevant.

\section{ACKNOWLEDGEMENT}

The research was supported by the entire faculty and post graduates of the department of orthodontics and dentofacial orthopedics and the authors extend sincere thanks to Prosommus Sleep Technology for their valuable support in successfully completing the research.

\section{REFERENCES}

1. Lawton HM, Battagel JM, Kotecha B. A comparison of the Twin Block and Herbst mandibular advancement splints in the treatment of patients with obstructive sleep apnoea: a prospective study. Eur J Orthod. 2005 Feb;27(1):82-90.

2. Fransson AMC, Tegelberg A, Leissner L, Wenneberg B, Isacsson G. Effects of a mandibular protruding device on the sleep of patients with obstructive sleep apnea and snoring problems: a 2-year follow-up. Sleep Breath. 2003 Sep; 7(3):131-41.

3. Shete CS, Bhad WA. Three-dimensional upper airway changes with mandibular advancement device in patients with obstructive sleep apnea. Am J Orthod Dentofacial Orthop. 2017 May;151(5):941-8.

4. Fransson AMC, Isacsson G, Leissner LC, Nasman AB, Alton MK. Treatment of snoring and obstructive sleep apnea with a mandibular protruding device: an open label study. Sleep Breath. 2001;5(1):23-34.

5. Huynh NT, Morton PD, Rompre PH, Papadakis A, Remise C. Associations between sleep disordered breathing symptoms and facial and dental morphometry, assessed with screening examinations. Am J Orthod Dentofacial Orthop. 2011 Dec;140(6):762-70.

6. Johal A, Battagel JM. An investigation into the changes in airway dimension and the efficacy of mandibular advancement appliances in subjects with obstructive sleep apnoea. Br J Orthod. 1999 Sep;26(3):205-10.

7. Fransson AMC, Tegelberg $\AA$, Svenson BAH, Lennartsson B, Isacsson G. Influence of mandibular protruding device on airway passages and dentofacial characteristics in obstructive sleep apnea and snoring. Am J Orthod Dentofacial Orthop. 2002 Oct;122(4):371-9.

8. Chen H, Lowe AA. Updates in oral appliance therapy for snoring and obstructive sleep apnea. Sleep Breath. 2013 May;17(2):473-86.

9. Hu J. Minimizing side effects: a retrospective case series analysis of tooth movement in oral appliance therapy. J Dent Sleep Pract. $2018 \mathrm{Mar} ; 26-27$.

10. Rvan CF, Love LL, Peat D, Fleetham JA, Lowe AA. Mandibular advancement oral appliance therapy for obstructive sleep apnoea: effect on awake calibre of the velopharynx. Thorax. 1999 Nov;54(11):972-7.

11. Bartolucci ML, Bortolotti F, Martina S, Corazza G, Michelotti A, Alessandri-Bonetti G. Dental and skeletal long-term side effects of mandibular advancement devices in obstructive sleep apnea patients: a systematic review with meta-regression analysis. Eur J Orthod. 2019;41(1):89-100.
12. Johns MW. Reliability and factor analysis of the Epworth sleepiness scale. Sleep. 1992 Aug;15(4):376-81.

13. Johns MW, Hocking B. Excessive daytime sleepiness: daytime sleepiness and sleep habits of Australian workers. Sleep. 1997;20(10):844-9.

14. American Academy of Sleep Medicine (AASM). International classification of sleep disorders. $3^{\text {rd }}$ ed. Darien, IL: AASM; 2014.

15. Ruehland WR, Rochford PD, O'Donoghue FJ, Pierce RJ, Singh P, Thornton AT. The new AASM criteria for scoring hypopneas: impact on the apnea hypopnea index. Sleep. 2009 Feb;32(2):150-7.

16. Revicki DA, Israel RG. Relationship between body mass indices and measures of body adiposity. Am J Public Health. 1986 Aug;76(8):992-4.

17. Sutherland K, Vanderveken OM, Tsuda H, Marklund M, Gagnadoux F Kushida CA, et al. Oral appliance treatment for obstructive sleep apnea: an update. J Clin Sleep Med. 2014 Feb;10(2):215-27.

18. Kushida CA, Littner MR, Morgenthaler T, Alessi CA, Bailey D, Coleman Junior J, et al. Practice parameters for the indications for polysomnography and related procedures: an update for 2005. Sleep. 2005 Apr;28(4):499-521.

19. Cohen R. Obstructive sleep apnea: oral appliance therapy and severity of condition. Oral Surg Oral Med Oral Pathol Oral Radiol Endodont. 1998 Apr;85(4):388-92.

20. Johal A, Haria P, Manek S, Joury E, Riha R. Ready-made versus custommade mandibular repositioning devices in sleep apnea: a randomized clinical trial. J Clin Sleep Med. 2017 Feb;13(2):175-82.

21. Vanderveken OM, Dieltjens M, Wouters, K, De Backer WA, Van de Heyning PH, Braem MJ. Objective measurement of compliance during oral appliance therapy for sleep- disordered breathing. Thorax. 2013 Jan;68(1):91-6.

22. Guilleminault C, Dement WC. Sleep apnea syndromes. New York: Alan R Liss, Inc.; 1978.

23. Guilleminault C, Dement WC. Sleeping and waking disorders: indications and techniques. Menlo Park: Addison-Wesley; 1982.

24. Bernhold M, Bondemark L. A magnetic appliance for treatment of snoring patients with and without obstructive sleep apnea. Am J Orthod Dentofacial Orthop. 1998 Feb;113(2):144-55

25. Bonham PE, Currier GF, Orr WC, Othman J, Nanda RS. The effect of a modified functional appliance on obstructive sleep apnea. Am J Orthod Dentofacial Orthop. 1988 Nov;94(5):384-92.

26. Gavish A, Vardimon AD, Rachima H, Bloom M, Gazit E. Cephalometric and polysomnographic analyses of functional magnetic system therapy in patients with obstructive sleep apnea. Am J Orthod Dentofacial Orthop. 2001;120:169-77.

27. Lowe AA, Gionhaku N, Takeuchi K, Fleetham JA. Three-dimensional CT reconstructions of tongue and airway in adult subjects with obstructive sleep apnea. Am J Orthod Dentofacial Orthop. 1986 Oct;90(5):364-74.

28. Ferguson K. Oral appliance therapy for obstructive sleep apnoea; finally evidence you can sink your teeth into. Am J Resp Critic Care Med. 2001 Mav;163(6):1294-5.

29. Acharya UR, Joseph KP, Kannathal N, Lim CM, Suri JS. Heart rate variability: a review. Med Biol Eng Comput. 2006 Dec;44(12):1031-51.

30. Guilleminault C, Winkle R, Connolly S, Melvin K, Tilkian A. Cyclical variation of the heart rate in sleep apnoea syndrome: mechanisms, and usefulness of $24 \mathrm{~h}$ electrocardiography as a screening technique. Lancet. 1984 Jan;323(8369):126-31.

31. Gauthier L, Laberge L, Beaudry M, Laforte M, Rompre PH, Lavigne GJ Mandibular advancement appliances remain effective in lowering respiratory disturbance index for 2.5-4.5 years. Sleep Med. 2011 Oct;12(9):844-9.

32. Gotsopoulos H, Kelly JJ, Cistulli PA. Oral appliance therapy reduces blood pressure in obstructive sleep apnea: a randomized, controlled trial. Sleep. 2004 Aug;27(5):934-41.

33. Johns MW. A new method for measuring daytime sleepiness. Sleep. 1991 Dec;14(6):540-5.

34. Cozza P, Polimeni A, Ballanti F. A modified monobloc for the treatment of obstructive sleep apnoea in paediatric patients. Eur J Orthod. 2004 Oct:26(5):523-30.

35. Hammond RJ, Gotsopoulos H, Shen G, Petocz P, Cistulli PA, Darendeliler MA. A follow- up study of dental and skeletal changes associated with mandibular advancement splint use in obstructive sleep apnea. Am J Orthod Dentofacial Orthop. 2007 Dec;132(6):806-14.

36. Tan YK, L'Estrange PR, Luo YM, Smith C, Grant HR, Simonds AK, et al. Mandibular advancement splints and continuous positive airway pressure in patients with obstructive sleep apnoea: a randomized crossover trial. Eur J Orthod. 2002 Jun;24(3):239-49.

37. Giannasi LC, Almeida FR, Nacif SR, Oliveira LV. Efficacy of an oral appliance for the treatment of obstructive sleep apnea. Int J Prosthodont. 2013;26:334-9. 
38. Blanco J, Zamarrón C, Pazos MTA, Lamela C, Quintanilla DS Prospective evaluation of an oral appliance in the treatment of obstructive sleep apnea syndrome. Sleep Breath. 2005;9(1):20-5.

39. Schmidt-Nowara WW, Mead TE, Hays MB. Treatment of snoring and obstructive sleep apnea with a dental orthosis. Chest. 1991 Jun;99(6):1378-85.

40. Johnson LM, Arnett GW, Tamborello JA, Binder A. Airway changes in relationship to mandibular posturing. Otolaryngol Head Neck Surg. 1992;106:143-8.

41. Eveloff SE, Rosenberg CL, Carlisle CC, Millman RP. Efficacy of a Herbst mandibular advancement device in obstructive sleep apnea. Am J Respir Crit Care Med. 1994 Apr;149(4 Pt 1):905-9.

42. Bibby RE, Preston CB. The hyoid triangle. Am J Orthod. 1981 Jul;80(1):92-7.
43. Tangugsorn V, Skatvedt O, Krogstad O, Lyberg T. Obstructive sleep apnea: a cephalometric study. Part I. Cervico-craniofacial skeletal morphology. Eur J Orthod. 1995 Feb;17(1):45-56.

44. Pracharktam N, Nelson S, Hans MG, Broadbent BH, Redline S, Rosenberg C, et al. Cephalometric assessment in obstructive sleep apnea. Am J Orthod Dentofacial Orthop. 1996;109:410-9.

45. Tourné LP. Growth of the pharynx and its physiologic implications. Am J Orthod Dentofacial Orthop. 1991 Feb;99(2):129-39.

46. Bondemark L, Lindman R. Craniomandibular status and function in patients with habitual snoring and obstructive sleep apnoea after nocturnal treatment with a mandibular advancement splint: a 2 -year follow-up. Eur J Orthod. 2000 Feb;22(1):53-60.

47. Kyung SH, Park YC, Pae EK. Obstructive sleep apnea patients with the oral appliance experience pharyngeal size and shape changes in three dimensions. Angle Orthod. 2005 Jan;75(1):15-22.

\section{APPENDICES}

Appendix I. Definition of cephalometric reference planes.

\section{Reference Planes}

NF - Nasal floor; a line connecting anterior nasal spine (ANS) and posterior nasal spine (PNS).

OP - Occlusal plane; a line connecting Mc and the incisal tip of the most prominent maxillary incisor (is).

MP - Mandibular plane; line tangent to the lower border of the body of the mandible through menton (Go-Me).

Base of $\mathrm{C} 2\left(2^{\text {nd }}\right.$ cervical vertebrae $)-$ a line connecting aC2 and $\mathrm{pC} 2$.

Base of $\mathrm{C} 3$ ( $3^{\text {rd }}$ cervical vertebrae $)-a$ line connecting $\mathrm{aC} 3$ and $\mathrm{pC} 3$.

Appendix II. Definition of cephalometric variables measured in the study.

\section{Pharyngeal dimensions}

$\mathrm{P} 0$ - The linear distance between the posterior pharyngeal wall and posterior soft palate along NF ( $\mathrm{pP} 0-\mathrm{aP} 0)(\mathrm{mm})$;

$\mathrm{P} 1$ - The linear distance between the posterior pharyngeal wall and posterior soft palate along OP (pP1 - aP1) (mm);

P2 - The linear distance between posterior and anterior pharyngeal walls along MP (pP2 - aP2) (mm);

P3 - The linear distance between posterior and anterior pharyngeal walls along the base of C2 (pP3 - aP3) (mm);

$\mathrm{P} 4$-The linear distance between posterior and anterior pharyngeal walls along the base of $\mathrm{C} 3(\mathrm{pP} 4-\mathrm{aP} 4)(\mathrm{mm})$.

\section{Velum dimensions}

PNS - V Length of velum; distance between PNS and V (mm); LV- UV Thickness of velum; distance between LV and $\mathrm{UV}(\mathrm{mm})$.

\section{Hyoid position}

Hy-NF: Perpendicular distance from NF to $\mathrm{Hy}(\mathrm{mm}) ; \mathrm{Hy}-\mathrm{OP}$ : Perpendicular distance from OP to $\mathrm{Hy}(\mathrm{mm}) ; \mathrm{Hy}-$ MP: Perpendicular distance from MP to Hy $(\mathrm{mm})$;

Hy-aC2: Linear distance between Hy and aC2 (mm); Hy-aC3: Linear distance between Hy and aC3 ( $\mathrm{mm}$ ).

\section{Mandibular position}

Angular measurement

Facial angle: Angle formed by FH- NPog.

Linear measurement

$\mathrm{N} \perp$ Pog: Horizontal distance between a perpendicular line from nasion to Pog. 